Aksiologiya: Jurnal Pengabdian Kepada Masyarakat

Vol.5, No. 2, Mei 2021 Hal 248 - 254

ISSN 2528-4967 (print) dan ISSN 2548-219X (online)

\title{
Pendampingan Perangkat Desa untuk Pelatihan Pembuatan Infografis Data Kependudukan Desa
}

\author{
Etis Sunandi ${ }^{1}$, Dian Agustina ${ }^{2}$, Herlin Fransiska ${ }^{3^{*}}$ \\ ${ }^{1,2,3}$ Program Studi S1 Statistika FMIPA Universitas Bengkulu \\ Email : hfransiska@unib.ac.id
}

\begin{abstract}
ABSTRAK
Keterbukaan informasi merupakan hal yang sangat penting di era digital saat ini. Pengabdian kepada masyarakat yang dilakukan bertujuan untuk peningkatan skill perangkat desa sehingga mampu memberikan informasi yang valid, informatif dan terperinci tentang kependudukan desa. Informasi data desa yang tersaji secara menarik, informatif dan terperinci akan menjelaskan kondisi desa kepada seluruh masyarakat desa dan umum. Lokasi pendampingan ialah Desa Pekik Nyaring Kecamatan Pondok Kelapa, Kabupaten Bengkulu Tengah. Desa ini termasuk kedalam daerah pemekaran menjadi kabupaten baru sehingga keterbukaan data penduduk sangat penting. Pelatihan pembuatan publikasi data desa dilakukan dalam tiga tahap yaitu sosialisasi, pelatihan, publikasi hasil pelatihan. Sosialisasi yang disambut baik oleh kepala desa dan perangkatnya menjadikan pelatihan dapat dilaksanakan dengan baik. Data kependudkan desa yang dianalisis secara statistik deskriptif menggunakan Ms.Excel dengan pivot table, chart, data validation, dan fungsi statistika yang telah tersedia. Selanjutnya hasil analisis deskriptif di analisis dan di desain menjadi menarik dan dipublikasikan. Hasil publikasi dapat menjelaskan semua informasi kependudukan desa seperti jumlah penduduk, pekerjaan, agama, tingkat pendidikan, demografi desa, kepala keluarga dan jumlah penduduk. Pendampingan yang mendapat respon positif dengan ditunjukkannya adanya publikasi data desa pertama kali yang berbentuk infografis desa yang dapat diperoleh di tempat umum.
\end{abstract}

Kata Kunci: data kependudukan; infografis; pendampingan.

\section{Assistance of Village Apparatus for Training on Making Village Population Data Infographics}

ABSTRACT

Information disclosure is very important in the digital era. Community service aims to improve the skills of village officials so that they are able to provide valid, informative and detailed information on village population. The village data information presented in an interesting, informative and detailed manner will explain the condition of the village to all village communities and the general public. The location of the assistance was Pekik Nyaring Village, Pondok Kelapa 
District, Bengkulu Tengah Regency. This village is a region that has become a new regency so open disclosure of population data is very important. The training on making village data publications was carried out in three stages: socialization, training, publication. The socialization was welcomed by the village head and his apparatus. Village population data were analyzed using descriptive statistics using Ms. Excel with pivot tables, charts, validation data, and statistical functions that were available. Furthermore, the results of descriptive analysis are analyzed and designed to be interesting and published. The results of the publication can explain all village population information such as population, occupation, religion, education level, village demographics, family heads and population. Assistance that received a positive response by showing the existence of the first village data publication in the form of village infographics that can be obtained in public places.

Keywords: population data; infographic; accompaniment.

\section{PENDAHULUAN}

Desa adalah kesatuan masyarakat hukum yang memiliki batas wilayah yang berwenang untuk mengatur dan mengurus urusan pemerintahan, kepentingan masyarakat setempat berdasarkan prakarsa masyarakat, hak asal usul, dan/atau hak tradisional yang diakui dan dihormati dalam sistem pemerintahan Negara Kesatuan Republik Indonesia (NKRI) (Amalia and Syawie 2015). Dengan kata lain, desa adalah kesatuan wilayah yang dihuni oleh sejumlah keluarga yang mempunyai sistem pemerintahan sendiri. Pemerintahan desa adalah penyelenggaraan urusan pemerintahan dan kepentingan masyarakat setempat dalam sistem pemerintahan NKRI (Zainudin 2016). Pejabat Pengelola Keuangan Daerah yang selanjutnya disingkat PPKD adalah Kepala Satuan Kerja Pengelola Keuangan Daerah yang mempunyai tugas melaksanakan pengelolaan APBD dan bertindak sebagai bendahara umum daerah (Peraturan Menteri Desa Pembangunan Daerah Tertinggal Dan Transmigrasi No 84 Tahun 2015 2015).

Sistem kependudukan yang selalu up to date sangat dibutuhkan untuk kegiatan pelayanan masyarakat di bidang administrasi kependudukan dan kebutuhan informasi pada suatu pemerintahan baik di daerah maupun pusat. Namun kondisi yang terjadi di masyarakat menunjukkan bahwa pelayanan masyarakat tersebut belum maksimal sehingga kurang efisien dalam pengolahan informasinya. Administrasi kependudukan merupakan salah satu bagian yang sangat penting di pemerintahan guna meningkatkan pelayanan kepada publik (Endang Amalia 2017).

Administrasi Kependudukan adalah rangkaian kegiatan penataan dan penertiban dalam penerbitan dokumen dan Data Kependudukan melalui Pendaftaran Penduduk, Pencatatan Sipil, pengelolaan informasiAdministrasiKependudukan serta pendayagunaan hasilnya untuk pelayanan publik dan pembangunan sektor lain (RI 2006).

Salah satu dokumen kependudukan ialah KTP. Kartu Tanda Penduduk, selanjutnya disingkat KTP, adalah identitas resmi Penduduk sebagai bukti diri yang diterbitkan oleh Instansi Pelaksana yang berlaku di seluruh wilayah Negara Kesatuan 
Republik Indonesia (RI 2006). Saat ini KTP telah berbentuk elektronik yang disebut dengan E-KTP. KTP Elektronik adalah dokumen kependudukan yang memuat sistem keamanan/ pengendalian baik dari sisi administrasi ataupun teknologi informasi dengan berbasis pada database kependudukan nasional (Febriharini 2016). Pendataan pendudukdaninformasi datapenduduk menjadi sangat penting karena keterbukaan informasi merupakan hal yang sangat penting di era 4.0. Berdasarkan UU Nomor 16, 1997 data adalah informasi yang berupa angka tentang karakteristik (ciri-ciri khusus) suatu populasi yang dalam hal ini adalah desa sehingga informasi menjadi mahal saat informasi tersaji secara menarik, informatif dan terperinci.

Statistik adalah data yang diperoleh dengan cara pengumpulan, pengolahan, penyajian, dan analisis serta sebagai sistem yang mengatur keterkaitan antar unsur dalam penyelenggaraan statistic (UU Nomor 16 1997).

Pada saat ini pembangunan berwawasan kependudukan adalah pembangunan yang menempatkan isu perkembangan kependudukan dan pembangunan keluarga sebagai titik sentral dalam pembangunan berkelanjutan di Indonesia. Pemahaman penduduk mengenai kependudukan diharapkan dapat membantu agar mampu mempersiapkan diri untuk memiliki pengetahuan, pemahaman, kesadaran dan sikap perilaku berwawasan kependudukan (Sitorus 2017). Pembangunan dapat dilakukan saat kita memiliki data sebagai pondasi awal.

Pelatihan Ms.Excel untuk pengelolaan database kependudukan dalam bentuk statistic deskriptif yang selanjutnya dipublikasikan menjadi infografis desa. Desa yang menjadi tempat pendampingan ialah desa di kabupaten baru.

Tujuan yang ingin dicapai melalui kegiatan ini adalah memberikan pelatihan kepada perangkat desa di Pekik Nyaring, Kecamatan Pondok Kelapa, Kabupaten Bengkulu Tengah tentang bagaimana pengolahan database kependudukan dan analisis deskriptifnya dengan menggunakan program Ms. Excel sebagai bahan publikasi infografis desa.

Microsoft Excel umumnya dikenal sebagai software pengolah angka atau bisa dikatakan sebagai program aplikasi lembar yang berfungsi mengolah data secara otomatis seperti perhitungan, rumus, pemakaian fungsi, tabel, pembuatan grafik, dan manajemen data untuk menciptakan data informasi digunakan dalam rangka pengambilan keputusan (Petro and Swatan 2019). Dengan memberikan pelatihan kepada perangkat desa terkait Ms. Excel diharapakan perangkat desa dapat menyajikan data desa dengan bentuk deskriptif. Selanjutnya hasil pengolahan dipubikasikan dalam bentuk infografis yang merupakan salah satu elemen visual penting dalam dunia jurnalistik adalah Infografis, terutama pada media massa cetak dan 
media elektronik. Infografis digubakan agar dapat mempermudah pembaca memahami narasi sebuah berita maupun memahami proses sebuah penelitian ilmiah yang dipublikasikan (Saptodewo 2014).

\section{METODE PENELITIAN}

Metodologi yang digunakan dalam pendampingan ini diuraikan secara jelas dan terinci sebagai berikut:

1. Sosialisasi

Pada awal kegiatan dilakukan sosialisasi mengenai pentingnya melakukan pengolahan database kependudukandanmenyajikannya dalam bentuk tabel dan grafik sebagai analisis deskriptifnya.

2. Pelatihan pengolahan dan analisis deskriptif.

Langkah selanjutnya memberikan pelatihan pada perangkat desa dari tentang bagaimana prosedur pengolahan database selanjutnya menyajikan data tersebut dan membuat statistik deskriptifnya dengan menggunakan Ms. Excel. Pada kegiatan ini juga dilakukan diskusi dengan perangkat desa mengenai pengolahan database kependudukan yang diperlukan dan praktis.

3. Latihan pengolahan dan analisis deskriptif database kependudukan.

Perangkat desa diberikan latihan untuk melakukan proses pengolahan dan analisis deskriptif database kependudukan yaitu data-data penduduk dengan menggunakan Ms. Excel.
Sehingga setelah diadakannya kegiatan pengabdian ini, mereka bisa melakukan pengolahan data dan menyajikan data dengan praktis dan informatif.

4. Cetak hasil pengolahan data

Pada kegiatan ini hasil pengolahan dan dan analisis data dipublikasikan dalam bentuk poster yang di tempelkan di kantor desa ataupun tempat-tempat yang ramai lainnya.

\section{HASIL DAN PEMBAHASAN}

Koordinasi dilakukan oleh tim kepada perangkat desa sebagai bentuk inisiasi kebutuhan desa tentang kebutuhan publikasi desa. Adapun perangkat desa memiliki susuan sebagai berikut:

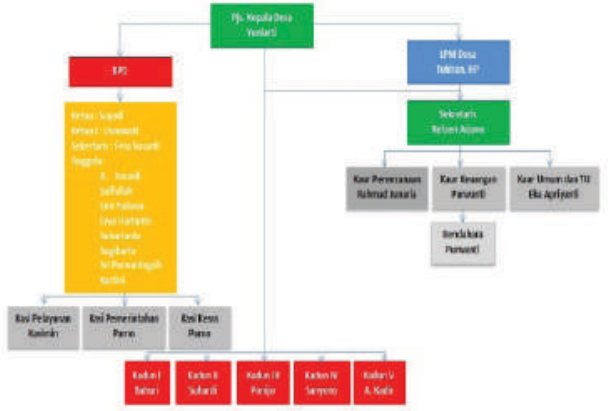

Gambar 1 Susunan Perangkat Desa Pekik Nyaring

Selanjutnya ialah sosialisasi, yang dilakukan oleh tim dengan perangkat desa, mengenai pentingnya statistik deskriptif dalam peningkatan kualitas informasi data yang diberikan oleh perangkat desa dan memperkenalkan pemanfaatan fitur pada Ms.Excel sebagai penunjang analisis deskriptif data dengan tema: "pentingnya melakukan pengolahan database kependudukan dan menyajikannya dalam bentuk tabel dan grafik sebagai analisis deskriptifnya". Kegiatan 
sosialisasi dapat dilihat pada gambar berikut:

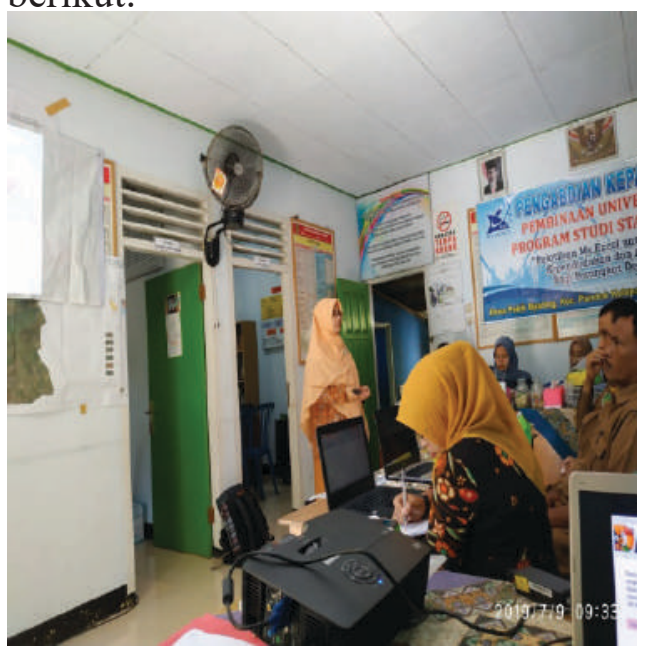

Gambar 2 Kegiatan Sosialisasi

Kegiatan selanjutnya adalah pelatihan pengolahan dan analisis deskriptif untuk perangkat Desa Pekik Nyaring. Kegiatan ini tim PPM dibantu oleh dua mahasiswa Program Studi Statistika FMIPA Universitas Bengkulu.

Pelatihan ini juga membutuhkan alat berupa computer atau laptop yang telah dilengkapi dengan Ms. Excel. Karena keterbatasan alat di Desa Pekik Nyaring, maka tim menyiapkan sebanyak 9 laptop demi keberlangsungan kegiatan pelatihan ini. Pada tahap pelatihan, dilakukan pengenalan menggunakan Ms.Excel dalam membuat grafik, table, pivot dan lain-lain. Kegiatan pelatihan dapat dilihat pada gambar berikut:

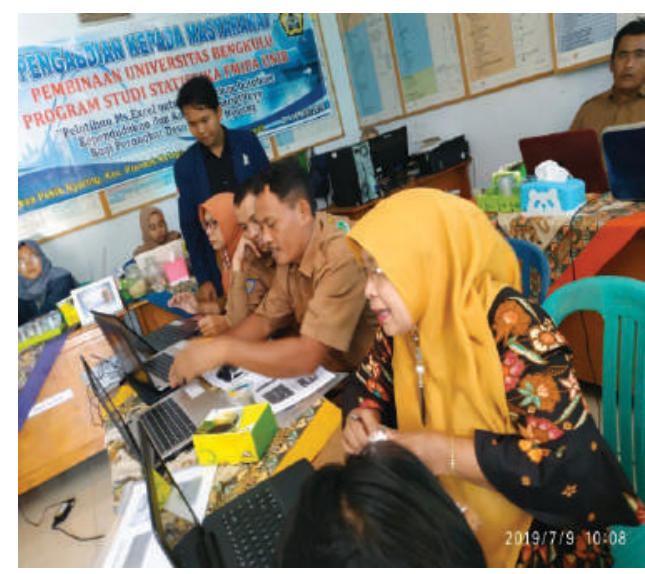

Gambar 3 Pelatihan Analisis Statistic Deskriptif Data Desa

Pada sesi pelatihan pengolahan data dan analisis deskriptif dilakukan selama 180 menit. Setelah pelatihan, peserta dapatmencobamengeksplorasi materi pembelajaran masing-masing.

Statistik deskriptif data desa yang telah tersaji dalam bentuk table, grafik, dan lain lain selanjutnya di desain menjadi semenarik mungkin sehingga publikasi infografis menjadi menarik, informative dan terperinci.

Kegiatan terakhir dari rangkaian PPM ini adalah pembuatan infografis. Pada kegiatan ini hasil pengolahan dan analisis data dipublikasikan dalam bentuk poster infografis yang ditempelkan di kantor desa. Berikut kegiatannya:

Hasil pelatihan yang selanjutnya dipublikasikan memberikan informasi kepada masyarakat desa tentang data kependudukan. Dapat dilihat pada gambar berikut tim mengunjungi kantor desa yang telah menempelkan publikasi data desa pada kantor desa. 


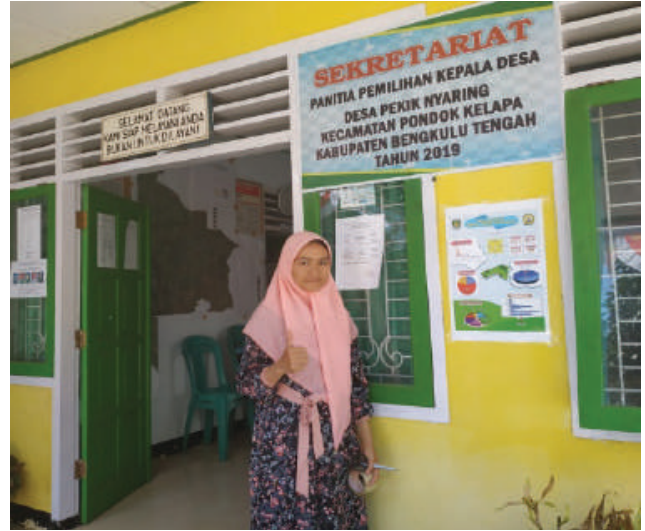

Gambar 4 Publikasi di Kantor Desa

Adapun hasil pengolahan yang dipublikasikan ialah sebagai berikut:

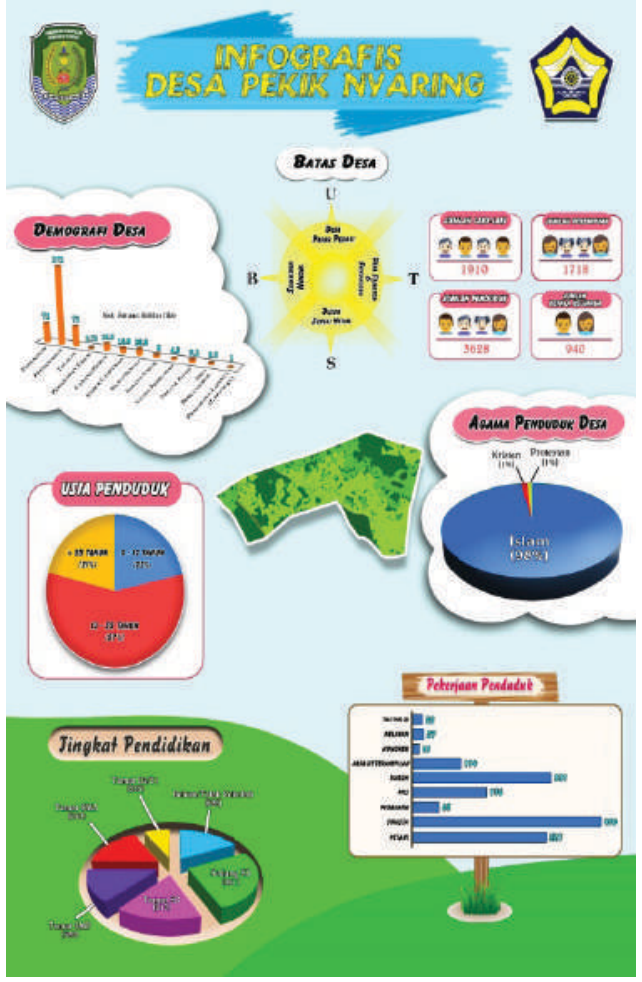

Gambar 5 Infografis Desa Pekik

\section{SIMPULAN}

Nyaring

Evaluasi akan dilakukan setelah selesai kegiatan sosialisasi, pelatihan, dan publikasi ialah yaitu pada bulan ke tiga dan ke empat pengabdian. Kriteria yang digunakan adalah dengan melihat keberlanjutan perangkat desa dalam melakukan pengolahan dan penyajian data tersebut. Bentuk pencapaian seperti telah terdata seluruh database kependudukan desa, dan telah dapat melakukan analisis deskriptif data kependudukan tersebut dan menampilkan data tersebut sebagai salah satu indikator profil desa secara mandiri. Pada akhir kegiatan ini adalah pembuatan infografis Desa Pekik Nyaring.

\section{DAFTAR PUSTAKA}

Amalia, Ayu Diah and M. Syawie. 2015. "Pembangunan

Kemandirian Desa Melalui Konsep Pemberdayaan: Suatu Kajian Dalam Perspektif Sosiologi." Pembangunan Kemandirian Desa Melalui Konsep Pemberdayaan: Suatu Kajian Dalam Perspektif Sosiologi.

EndangAmalia, Yayat Supriatna. 2017. "Perancangan Sistem Informasi Administrasi Kependudukan Sebagai Pengembangan Egovernment." Prosiding Seminar Ilmu Komputer Dan Teknologi Informasi.

Febriharini, Mahmuda Pancawisma. 2016. "Pelaksanaan Program e KTP Dalam Rangka Tertib Administrasi Kependudukan." Serat Acitya -Jurnal Ilmiah UNTAG Semarang.

Peraturan Menteri Desa Pembangunan Daerah Tertinggal Dan Transmigrasi No 84 Tahun 2015. 2015. "Susunan Organisasi Dan Tata Kerja Pemerintah Desa." Ekp 13(3):1576-80.

Petro, San and Karnadi Handoko Swatan. 2019. "Pelatihan Microsoft Excel Sebagai Penunjang Ketrampilan Hard Skill Bagi Siswa Pada Smk Ypsei Palangka Raya." JurnalAbdimas BSI: Jurnal Pengabdian Kepada Masyarakat. 
RI, DPR. 2006. "UU No.23 Tahun 2006." Motivation and Emotion 30(3):83.

Saptodewo, Febrianto. 2014. "Desain Infografis Sebagai Penyajian Data Menarik." Jurnal Desain.

Sitorus, Muhammad Ancha. 2017. "Integrasi Pendidikan Kependudukan Kedalam Kurikulum Dalam Rangka Pencapaian Target Sustainable Development Goals (Sdgs) Di Indonesia." Prosiding Seminar Nasional Tahunan Fakultas Ilmu Sosial Universitas Negeri Medan Tahun.

UU Nomor 16. 1997. "UndangUndang Tentang Statistik 1." Badan Pusat Statistik 1-22.

Zainudin, Arif. 2016. "Model Kelembagaan Pemerintahan Desa." Jurnal Ilmu Pemerintahan: Kajian Ilmu Pemerintahan Dan Politik Daerah. 